\title{
PRODUÇÃO DE VÍDEOS: UMA INTERVENÇÃO PEDAGÓGICA NO ENSINO E APRENDIZAGEM DE ESPANHOL COMO LÍNGUA ADICIONAL
}

\section{Video Production: A Pedagogical Intervention in Teaching and Learning of Spanish as an Additional Language}

Fernanda Soares Luz ${ }^{1}$

Adelson Siqueira Carvalho

\begin{abstract}
Resumo: Este artigo tem como objetivo apresentar os resultados de uma intervenção pedagógica realizada com treze estudantes que concluíram o curso de espanhol do Centro de Línguas de um Instituto Federal de Educação Ciência e Tecnologia. Essa intervenção ocorreu por meio de um curso de extensão que visou investigar de que maneira a produção de vídeos pode promover melhorias no processo de ensino e aprendizagem do espanhol como língua adicional, de modo a torná-lo mais interativo e ativo. Para isso, foi elaborada e aplicada uma WebQuest para nortear a realização de tarefas propondo a produção de vídeos e o uso de ferramentas digitais como o software Canva e aplicativos de edição de imagens. A pesquisa é de natureza qualitativa e foi conduzida como uma intervenção pedagógica. Os dados coletados por meio de observação e questionários foram analisados pelo método de análise de conteúdos e evidenciam resultados positivos para a utilização de vídeos como produção na aprendizagem de espanhol como língua adicional.
\end{abstract}

Palavras-chave: Vídeo como produção. WebQuest. Ensino e aprendizagem de espanhol. Intervenção Pedagógica.

Abstract: This article aims to present the results of a pedagogical intervention carried out with thirteen students who have finished the Spanish course at the Language Center of a Federal Institute of Education, Science and Technology. This intervention occurred through an extension course that aimed to investigate how video production can improve the process of teaching and learning Spanish as an additional language, to make it more interactive and active. For that, a WebQuest was developed and applied to guide the accomplishment of tasks proposing the production of videos and the use of digital tools like the software Canva and image editing applications. The research has a qualitative nature and was conducted as a pedagogical intervention. The data collected through observation and questionnaires were analyzed through the Content Analysis Method and show positive results for the use of videos as production in learning Spanish as an additional language.

Keywords: Video as production. WebQuest. Spanish teaching and learning. Pedagogical Intervention.

\footnotetext{
${ }^{1}$ Mestra em Ensino e suas Tecnologias (IFFluminense). Especialista em Língua Espanhola (FAFIC). Licenciada em Letras - Português/ Espanhol (UNIMES) e Português/Inglês (FFSD). Professora de espanhol do IFFluminense. Orcid: https://orcid.org/0000-0002-5644-4343.E-mail: fernandasluz@gmail.com.

${ }^{2}$ Doutor em Informática na Educação (UFRGS). Mestre em Engenharia de Produção (UENF). Especialista em Produção e Sistemas (IFFluminense). Graduado em Tecnologia de Automação Industrial (IFFluminense). Professor de Automação do IFFluminense. Orcid: https://orcid.org/0000-0003-0641-1903. E-mail: acarval@iff.edu.br.
} 


\section{Introdução}

Diante da era globalizada e tecnológica em que a sociedade se encontra imersa, as tecnologias digitais são apontadas como recursos pedagógicos importantes para a construção de um processo de ensino e aprendizagem que corresponda às exigências e aos desafios contemporâneos (SILVA; MARIANO; FINARDI, 2018).

Nesse cenário, Porto (2017) ressalta que por estar cada vez mais presente na vida cotidiana, o ambiente virtual vem sendo utilizado pelos aprendizes não só como entretenimento e comunicação, mas como fonte de pesquisa e acesso a inúmeras informações.

Para Paiva (2001), apesar de esse ambiente apresentar pontos positivos tais como: uma grande variedade de informações dispostas em um ambiente multimídia e possibilitar a rapidez no acesso a essas informações, também apresenta aspectos negativos. Para a autora, o excesso de informação (que nem sempre é confiável) e o fato de que nem todo material possui qualidade, são alguns dos aspectos desfavoráveis à utilização da internet como ambiente de construção do conhecimento. No entanto, apesar das desvantagens do seu uso para fins educacionais, a autora afirma ser um local privilegiado para a aprendizagem de línguas, por ser capaz de promover variadas oportunidades de interação e a "[...] possibilidade de inserção em uma comunidade mundial de aprendizes e falantes da língua e consequente comunicação significativa enriquecida com negociação de sentido em contextos reais." (PAIVA, 2001, p. 114).

Diante do potencial pedagógico da internet para fins educacionais, Bernie Dodge, professor da Universidade de San Diego (EUA), em parceria com seu ex-aluno de graduação, Tom March, desenvolveu, em 1995, uma proposta que permite que alunos adquiram e integrem conhecimentos por meio da web, a WebQuest (WQ) (MENDES, 2018).

A escolha pelo uso desse recurso tecnológico para esta pesquisa respalda-se em trabalhos que evidenciam os benefícios da sua utilização no âmbito educacional. Segundo Abar e Barbosa, 2008; Bottentuit Júnior, 2013; Porto, 2017; Mendes, 2018; e Santos, 2019, a WQ é capaz de ampliar as possibilidades de ensino e favorecer situações de aprendizagem mais interativas, ativas e autênticas.

Nesse contexto, Silva (2016), destaca que as atividades decorrentes da utilização de vídeos, além de fomentarem a interação, a autonomia e o espírito crítico, apresentam-se como um importante aliado ao processo de ensino e aprendizagem. Além disso, Tumolo (2014) enfatiza que quando utilizado como produção, o vídeo pode tornar o aprendiz mais ativo e participativo, uma vez que "[...] ser produtor pode acrescentar a dimensão de autoria para aprendizes, que deixam de ter o papel somente receptivo [...]" (TUMOLO, 2014, p. 227).

Assim sendo, este artigo tem como objetivo apresentar os resultados de uma intervenção pedagógica realizada com 13 estudantes que concluíram o curso de espanhol do Centro de Línguas de um Instituto Federal de Educação Ciência e Tecnologia. Essa intervenção foi realizada por meio de um curso de extensão que visou investigar de que maneira o uso de vídeos como produção pode promover melhorias no processo de ensino e aprendizagem do espanhol como língua adicional, de modo a torná-lo mais interativo e ativo. ${ }^{3}$

Como justificativa para a realização desta pesquisa, apresenta-se o resultado de uma pesquisa exploratória realizada com o público-alvo, que indicou a necessidade de

\footnotetext{
${ }^{3}$ Essa pesquisa foi aprovada pelo Conselho de Ética em Pesquisa (CEP). Está registrada na Plataforma Brasil, CAEE 26341419.3.0000.5583, Parecer 3.843.609.
} 
complementar e aprofundar os conhecimentos adquiridos no curso de espanhol por eles concluído por meio de atividades propostas a partir da utilização de tecnologias digitais.

O Ambiente Virtual de Aprendizagem (AVA) Edmodo foi utilizado para a postagem das atividades que constituem a WQ. Esse AVA foi utilizado tanto nas aulas presenciais como para postagem de trabalhos e interações que foram realizadas fora do espaço de sala de aula. Com isso, buscou-se criar espaços para a interação entre todos os envolvidos no processo de ensino e aprendizagem e promover a autonomia dos alunos, além de fomentar práticas linguísticas mais autênticas (MAYRINK; ALBUQUERQUE-COSTA, 2017).

Quanto aos procedimentos metodológicos, foi adotada uma abordagem predominantemente qualitativa. Como instrumentos e técnicas de coleta de dados foram utilizados dois questionários (um para uma pesquisa exploratória e outro para a avaliação final do curso) e observação. Os dados obtidos por meio dos questionários foram analisados de acordo com o método análise de conteúdo (BARDIN, 2009). A análise da observação foi realizada com base no referencial teórico adotado.

Além desta introdução, este artigo é composto por outras quatro seções. A seção dois apresenta o referencial teórico com discussões a respeito do potencial pedagógico dos vídeos como produção e da utilização da WQ no âmbito educacional. Na seção três, são descritos os aspectos metodológicos utilizados e as etapas desta pesquisa e, na seção quatro, são apresentados os resultados obtidos por meio da realização da intervenção pedagógica. Por fim, na seção cinco, as considerações a respeito deste estudo são destacadas.

\section{Referencial teórico}

O planejamento da intervenção pedagógica envolveu, primeiramente, uma pesquisa bibliográfica a respeito do referencial teórico que subsidiou a implementação dessa intervenção. Sendo assim, nesta seção discorre-se sobre o potencial pedagógico dos vídeos, em especial os propostos como produção e, em seguida, apresenta-se a WQ, outro recurso que orientou a realização das tarefas propostas durante a realização do curso de extensão em língua espanhola.

\subsection{O potencial pedagógico dos vídeos como produção}

De acordo com Tumolo (2014, p. 225), o recurso vídeo pode ser conceituado como “[...] todo o material audiovisual, com imagens em movimento". Nesse sentido, esse autor destaca, dentre outras características, o fato de ser uma ferramenta que motiva principalmente a geração atual de aprendizes por esses estarem habituados à era das imagens, o que aproxima o ensino e a realidade.

Moran (1995) apresenta as várias possibilidades de uso dessa ferramenta no contexto de sala de aula. Segundo esse autor, os vídeos podem ser usados para motivar, sensibilizar e despertar a curiosidade dos aprendizes ao introduzir um novo assunto. Além disso, ele evidencia o uso dos vídeos como videoaulas, enfatiza que os vídeos podem ser recursos utilizados para aproximar o aprendiz de temas que possam ser mais difíceis de serem assimilados e ainda ressalta sua importância como um recurso que possibilita o registro e a documentação de atividades desenvolvidas no espaço escolar, além de pontuar seu uso como um instrumento de avaliação.

Diante dessas possibilidades, Tumolo (2014) propõe formas de utilização que podem auxiliar a prática pedagógica e o contexto de aprendizagem, tais como produção dos próprios 
estudantes, de forma a torná-los mais ativos e participativos. Moran (2009) complementa destacando que, por serem dinâmicos, os vídeos são capazes de motivar o interesse pela aprendizagem. Além disso,

[...] também são um grande instrumento de comunicação e de produção. Os alunos podem criar facilmente vídeos a partir do celular, do computador, das câmeras digitais e divulgá-los imediatamente em blogs, páginas web, portais de vídeos como o YouTube. Os computadores e celulares deixaram de ser apenas ferramentas de recepção. Hoje, são também de produção. (MORAN, 2009, p. 1).

Segundo Díaz Rodríguez (2012) e Oliveira (2013), a utilização de vídeos como produção é especialmente motivadora. Pode desenvolver habilidades de expressão oral e escrita e fomentar o trabalho colaborativo, além de combater a timidez e desenvolver a criatividade. Em relação ao desenvolvimento da criatividade, Oliveira (2013) salienta que por meio de câmeras digitais ou smartphones os estudantes de uma língua estrangeira podem envolver-se em produção de roteiros, criar títulos e legendas e editar seus vídeos colocando efeitos especiais, por exemplo.

Para além da motivação e do desenvolvimento da criatividade, Oliveira (2013) e Bastos e Ramos (2015) ressaltam outros benefícios da utilização de vídeos no âmbito do processo de ensino e aprendizagem de línguas. Segundo essas autoras, o trabalho com o vídeo permite uma aprendizagem centrada no aluno e está orientado para o processo de ensino e não somente para o resultado. Além disso, possibilita o trabalho com atividades autênticas, requer o uso das quatro habilidades linguísticas (leitura, escrita, compreensão auditiva e expressão oral) e ainda pode ser capaz de aumentar a confiança e autonomia dos aprendizes.

Diante do exposto, cabe aos professores de línguas adicionais a adoção de novas abordagens de ensino que estimulem a descoberta e a construção do saber, por meio de atividades que fomentem a interação e o protagonismo do aprendiz.

\subsection{WebQuest}

De acordo com March (2004), a WQ pode ser caracterizada como uma tarefa autêntica que busca motivar a pesquisa, o desenvolvimento de habilidades e a participação em grupo. Para Dodge (1995), as WQ são definidas como pesquisas orientadas onde todas ou grande parte da informação e o conteúdo a ser manipulado pelo aprendiz encontram-se disponíveis na internet.

Além da definição proposta por seus criadores, outros autores como Abar e Barbosa (2008) e Bottentuit Júnior (2013) apresentam as suas. Segundo Abar e Barbosa (2008, p. 11), a "WebQuest é uma atividade didática, estruturada de forma que os alunos se envolvam no desenvolvimento de uma tarefa de investigação usando principalmente recursos da internet." Bottentuit Junior (2013, p. 18) destaca que a WQ é “[...] uma estratégia ou metodologia de pesquisa orientada na $W e b$ onde os alunos se envolvem na resolução de uma tarefa que exige dos mesmos a construção de um produto final.”.

Costa e Carvalho (2006) ressaltam que, pela sua autenticidade e capacidade de motivar o estudante a trabalhar com tarefas desafiantes, as WQ podem envolver ativamente os alunos e servirem como facilitadoras da aprendizagem, seja de forma individual ou colaborativa. Dessa forma, os alunos são capazes de elaborar produtos finais e apresentá-los de diversas formas, tais como a construção de blogs, livros digitais, ou jornais virtuais, canais ou páginas na internet (SANTOS, 2019). 
Segundo Abar e Barbosa (2008) a construção de uma WQ envolve seis componentes: introdução, tarefa, processo e recursos, avaliação, conclusão e créditos. A introdução deve instigar e desafiar a descoberta por meio de uma breve apresentação do tema a ser tratado. A tarefa - considerada a alma da WQ - deve propor, de forma clara, a produção de um produto final criativo. Os elementos, processo e recursos, consistem, respectivamente, em orientar claramente o que os alunos precisam fazer para executar a tarefa proposta e oferecer-lhes referências de sites, recursos e conteúdos disponíveis na web (textos, imagens, vídeos, entrevistas, entre outros) para execução dessa atividade. A avaliação, componente primordial de uma WQ, deve apresentar aos estudantes, de forma clara, de que maneira e quais fatores serão considerados nessa etapa. A conclusão tem por finalidade resumir o objetivo geral do que foi aprendido e deve apresentar-se como um convite a novos conhecimentos. Os créditos, que indicam as fontes, as imagens e os textos utilizados pelo autor da WQ, é um dos componentes especialmente indicados pelas autoras e, de acordo com outros autores, nem sempre são destacados.

Para a construção de uma WQ, não são necessários softwares específicos. Pode ser criada com o auxílio de programas como o Powerpoint e Google Slides ou por meio de recursos da web tais como plataformas on-line, que permitem cadastro gratuito. Dentro dessas possibilidades, apresentam-se o Google Sites, que é uma ferramenta digital gratuita criada pelo Google e a plataforma digital Wix, em sua versão gratuita, que permite a produção e edição de sites mediante um cadastro com a conta de um e-mail.

Finalizada a apresentação das potencialidades, dos componentes e recursos necessários para a criação de uma WQ, serão apresentados na próxima seção, os aspectos metodológicos da presente pesquisa.

\section{Procedimentos metodológicos}

Esta seção está dividida em duas subseções. Na subseção 3.1 são definidos o tipo de pesquisa, os instrumentos de coleta de dados e a metodologia utilizada na análise dos resultados. Na seção 3.2 são apresentadas as etapas da pesquisa.

\subsection{Caracterização da pesquisa}

Esta pesquisa teve como objetivo investigar de que maneira o uso de vídeos como produção pode promover melhorias no processo de ensino e aprendizagem do espanhol como língua adicional, de modo a torná-lo mais interativo e ativo. Para isso, foi elaborada e utilizada uma WebQuest para nortear a realização de tarefas propondo a produção de vídeos e o uso de ferramentas digitais como o software Canva e aplicativos de edição de imagens.

Trata-se de uma pesquisa com abordagem qualitativa do tipo intervenção pedagógica. Para Gerhardt e Silveira (2009, p. 32), a pesquisa qualitativa é aquela que se preocupa "[...] com aspectos da realidade que não podem ser quantificados, centrando-se na compreensão e explicação da dinâmica das relações sociais." Já Damiani (2012) destaca como principais características de uma pesquisa do tipo intervenção pedagógica: i) seu caráter aplicado, uma vez que busca contribuir para solução de problemas; ii) o intuito de produzir mudanças; iii) a manipulação de dados criados em contraposição aos existentes; iv) envolve uma avaliação apoiada em métodos científicos, ou seja, pautada pelo rigor e sistematização dos seus efeitos. Assim sendo, esse tipo de pesquisa pode ser definido como investigação que envolve planejamento e implementação de interferências (entendidas como inovações) com o propósito 
de produzir avanços e melhorias no processo de ensino e aprendizagem dos envolvidos, além de uma posterior avaliação sobre os resultados dessas interferências (DAMIANI et al., 2013).

A intervenção pedagógica foi desenvolvida por esta pesquisadora por meio de um curso de extensão. Visou realizar interferências - entendidas como melhorias (DAMIANI et al., 2013) no processo de ensino e aprendizagem do espanhol como língua adicional, de modo a torná-lo mais interativo e ativo. Foi desenvolvida com treze estudantes que concluíram o curso de espanhol do Centro de Línguas de um Instituto Federal de Educação Ciência e Tecnologia. Ocorreu no período de oito de outubro a doze de dezembro de 2019, totalizando 20 encontros presenciais com duas aulas de 45 minutos cada, somando 30 horas. As aulas ocorreram no laboratório do Centro de Línguas, às terças e quintas-feiras, das 18h às 19h30.

Como instrumentos de coleta de dados foram utilizados dois questionários, o inicial e o final. As informações referentes a esses questionários serão detalhadamente descritas na subseção 3.2.

A análise dos registros da observação foi realizada com base no referencial teórico adotado. Os dados coletados por meio dos questionários foram analisados de acordo com a análise de conteúdo (BARDIN, 2009). Inicialmente foi realizada uma análise prévia das respostas coletadas visando uma aproximação do material a ser analisado. Em seguida, conforme especifica Bardin (2009), foi realizada uma leitura reflexiva sobre o material obtido. Após a categorização dos temas evidenciados foi realizada a análise do corpus a partir da sua interpretação e inferência com a finalidade de tornar os resultados significativos e válidos (BARDIN, 2009).

Além do referencial teórico que subsidiou essa pesquisa, o presente estudo contou com mais duas etapas: uma pesquisa exploratória e uma intervenção pedagógica.

\subsection{Etapas da pesquisa}

A presente pesquisa possui três etapas. A primeira delas constitui-se por uma pesquisa bibliográfica, que foi apresentada no referencial teórico. A segunda etapa consistiu em uma pesquisa exploratória, a qual, de acordo com Gil (2010), objetiva aproximar o pesquisador do tema que se pretende investigar. Por fim, a etapa três compreendeu a implementação da intervenção pedagógica.

Para a pesquisa exploratória foi elaborado um questionário inicial, que objetivou traçar um perfil do público-alvo e conhecer as possibilidades de acesso às Tecnologias Digitais (bem como seu uso) como ferramentas que poderiam servir de auxílio às aulas durante o curso de extensão. Visou, ainda, analisar a necessidade de oferta desse curso e ajudar a delimitar o conteúdo a ser trabalhado. Compõem o público-alvo dessa pesquisa exploratória 70 ex-alunos do curso de espanhol do Centro de Línguas de um Instituto Federal de Educação Ciência e Tecnologia.

De acordo com os dados coletados na coordenação do Centro de Línguas, 70 alunos concluíram o curso de espanhol durante o período correspondente ao $1^{\circ}$ semestre do ano de 2016 e o $1^{\circ}$ semestre do ano de 2019 , período que corresponde ao tempo de trabalho da pesquisadora nesse local. Por meio da ficha individual de cada um desses alunos, foi possível identificar o número de telefone e $e$-mail, com o fim de viabilizar o contato entre a pesquisadora e os participantes dessa pesquisa.

Dentre os 70 ex-alunos contactados por meio do grupo criado no WhatsApp e do e-mail enviado aos que não utilizam esse aplicativo de mensagens, 43 responderam ao questionário. $\mathrm{O}$ 
levantamento de dados obtidos a partir da aplicação desse questionário norteou a escolha dos conteúdos a serem trabalhados e ajudou a traçar estratégias adequadas à elaboração do curso de extensão.

A partir da análise dos dados coletados na pesquisa exploratória, foi desenvolvida uma pesquisa do tipo intervenção pedagógica. Seu planejamento visou à elaboração de um curso de extensão, utilizando uma WQ que propôs atividades que requerem a utilização de tecnologias digitais e estão relacionadas especialmente à produção de vídeos com o intuito de favorecer situações de aprendizagem mais interativas e ativas. Já a implementação das interferências com vistas a promover melhorias nesse processo de ensino e aprendizagem, ocorreu por meio da realização do curso de extensão. A avaliação da implementação dessas interferências nesse curso deu-se por meio da observação feita pela pesquisadora e das respostas coletadas no questionário final.

Foram ofertadas 15 vagas para o curso de extensão. A opção por se trabalhar com esse quantitativo justifica-se pela necessidade de um acompanhamento mais personalizado, algo que é mais difícil quando se tem um grande número de participantes. No entanto, de acordo com os dados obtidos por meio da pesquisa exploratória, 43 ex-alunos do Centro de Línguas se mostraram interessados em participar do curso de extensão. Diante disso, foi necessário realizar uma seleção por meio de uma avaliação.

Após a divulgação, no grupo criado no WhatsApp e por e-mail, dos dias e horários em que o curso seria realizado, 19 candidatos realizaram sua inscrição para o processo seletivo. Esse processo foi realizado em língua espanhola e se deu por meio de quatro questões. As duas primeiras buscavam avaliar a expressão oral. Na terceira questão foi proposta uma atividade de compreensão auditiva e a última, buscou trabalhar com as habilidades de leitura e escrita.

As questões estavam relacionadas a alguns dos temas que seriam explorados no curso de extensão e buscou saber, ainda, o porquê da pretensão da realização do curso com o intuito de comprovar a disposição em participar do curso de extensão, além de analisar a fluência e a capacidade de comunicação na língua espanhola.

Apesar de 19 candidatos terem realizado sua inscrição para esse processo, 16 deles compareceram nos dias e horários agendados. No entanto, antes mesmo da divulgação final do resultado do processo seletivo, dois deles enviaram uma mensagem à professora pesquisadora comunicando a não possibilidade de participação por motivos pessoais. Diante disso, o curso contou, inicialmente, com 14 participantes.

Durante a realização do curso de extensão um dos participantes comunicou sua desistência, por motivos pessoais. Diante do exposto, considerou-se, para fins de análise dos resultados obtidos por meio do questionário final, o quantitativo de 13 participantes.

Esse questionário teve como objetivo avaliar, na percepção desses 13 participantes, se as atividades de produção de vídeos propostas pela WQ foram capazes de promover melhorias no processo de ensino e aprendizagem de espanhol como língua adicional, de modo a torná-lo mais interativo e ativo.

Na etapa três, que compreendeu a implementação da intervenção pedagógica, a WQ criada ${ }^{4}$ teve como tema "Viaje y cultura" e propôs, além da elaboração de um produto final, seis tarefas envolvendo, em sua maioria, a produção e a edição de vídeos. Elas foram realizadas

\footnotetext{
${ }^{4}$ O Google Sites foi o recurso escolhido para a produção da WQ. A opção por esse site deu-se por ser gratuito, apresentar facilidade de utilização e ferramentas necessárias para a construção de uma WQ de qualidade. Pode ser acessada em: https://sites.google.com/view/webquestviajeycultura/p\%C3\%A1gina-inicial
} 
em grupos formados por três ou quatro integrantes e propunham atividades que retomavam estruturas linguísticas anteriormente estudadas pelos participantes. Para a realização de cada uma delas, os participantes eram incentivados a recorrer à WQ, onde estavam dispostas informações sobre como cumpri-las.

Uma vez cumpridas essas tarefas, um membro de cada grupo as postava no Edmodo e, em seguida, todos os participantes eram incentivados a interagir, de maneira escrita, nessas postagens.

A avaliação da implementação da intervenção pedagógica contemplou, por parte da pesquisadora, a observação do processo de aprendizagem dos participantes durante a realização do curso de extensão. Já a aplicação do questionário final demonstrou o resultado da avaliação feita pelos 13 concluintes do curso. Essa avaliação será descrita na seção 4, que trata dos resultados e discussão.

\section{Resultados e discussão}

Inicialmente, na subseção 4.1 serão apresentados os dados coletados na pesquisa exploratória. Considerando que o curso de extensão desenvolvido foi planejado a partir dos resultados da pesquisa exploratória, na subseção 4.2 serão apresentados, concomitantemente, esse curso e os resultados obtidos por meio da observação. Por fim, na subseção 4.3 evidenciam-se os resultados obtidos pela aplicação do questionário final.

\subsection{Pesquisa exploratória}

O público-alvo apresenta-se com idades que variam entre 19 e 55 anos e possui, em sua maioria, curso superior incompleto. Todos eles estão vinculados ao Instituto Federal de Educação Ciência e Tecnologia, sendo estudantes e/ou servidores.

Sobre a utilização de recursos disponíveis na internet como apoio à aprendizagem, 100\% responderam que o fazem e apontam os vídeos disponíveis em língua espanhola como um dos principais recursos utilizados.

Diante desse dado e do fato de que os vídeos se apresentam como "[...] ferramentas que podem fomentar o processamento cognitivo, ajudando os alunos a abordar com maior profundidade o conteúdo que estão a aprender [...]” (BASTOS; RAMOS, 2015, p. 594), considerou-se oportuno trabalhar com atividades envolvendo a produção de vídeos pelos participantes.

A necessidade de utilizar tecnologias digitais e promover uma postura mais ativa do estudante no decorrer do curso de extensão surgiu a partir de uma avaliação sobre o curso de espanhol concluído pelo público-alvo. A Tabela 1 apresenta a avaliação dos 43 participantes dessa pesquisa a respeito desses dois temas.

Tabela 1 - Avaliação do curso de espanhol no Centro de Línguas

\begin{tabular}{cccccc}
\hline Assertivas & Excelente & Ótimo & Bom & Regular & Ruim \\
\hline $\begin{array}{c}\text { Uso de tecnologias } \\
\text { digitais durante as aulas }\end{array}$ & 9 & 12 & 18 & 3 & 1 \\
$\begin{array}{c}\text { Abertura para uma } \\
\text { participação mais ativa } \\
\text { dos estudantes }\end{array}$ & 24 & 12 & 6 & 1 & - \\
\hline
\end{tabular}

Fonte: Próprios autores, a partir de dados da pesquisa (2019). 
Ao serem questionados a respeito da utilização dessas tecnologias em sala de aula, as opiniões se mostraram bem divididas. Embora a maioria tenha avaliado como "bom", houve uma avaliação "ruim". Esse resultado foi considerado ao elaborar o curso de extensão, uma vez diferentes recursos digitais foram utilizados tanto por parte da professora pesquisadora quanto pelos participantes, ao realizarem as tarefas propostas.

Sobre a promoção de uma participação mais ativa, embora a maioria tenha opinado ser excelente, é possível perceber a necessidade de incentivar o protagonismo do estudante por evidenciar que alguns deles a consideram "bom" e "regular".

Além dos dados expostos, $100 \%$ dos participantes dessa pesquisa expressaram ter a necessidade de ampliar ou aprofundar o conhecimento na língua espanhola e o interesse em participar de um curso de extensão. Por fim, foi possível perceber a necessidade de se aprofundar conteúdos relacionados ao vocabulário e a estruturas gramaticais por meio das habilidades de leitura, escrita, prática oral e de compreensão auditiva, dados que foram considerados durante a criação da WQ.

\subsection{O curso de extensão e sua observação}

O curso de extensão desenvolvido propôs a realização de tarefas que requeriam a participação ativa dos estudantes. Após a realização e postagem, no Edmodo, de cada uma das tarefas propostas pela WQ elaborada todos os participantes eram incentivados a interagir, de maneira escrita, nessas postagens. Essas interações escritas, bem como toda produção escrita envolvida na elaboração das tarefas (o roteiro dos vídeos, por exemplo) eram corrigidas por meio da avaliação dinâmica.

De acordo com Figueiredo (2019), a avaliação dinâmica refere-se a uma

[...] abordagem que integra ensino e avaliação e visa fazer com que o aprendiz realize uma atividade avaliativa por meio da ajuda e da mediação do avaliador, de modo que o avaliador possa contribuir, por meio do diálogo, com o desenvolvimento cognitivo do aprendiz [...]. (FIGUEIREDO, 2019, p. 81).

Desse modo, a habilidade escrita foi sendo desenvolvida a partir do diálogo reflexivo entre os envolvidos no processo de ensino e aprendizagem da língua. As interações escritas realizadas no Edmodo eram lidas em conjunto com os alunos. Nesse momento a professora pesquisadora realizava perguntas sobre estruturas gramaticais já apresentadas no curso de espanhol concluído por eles e levantava reflexões sobre as mesmas, de modo que os participantes, ao recordá-las, pudessem ter um novo olhar sobre o que fora escrito e corrigissem o que considerassem necessário.

De maneira geral, a observação realizada pela professora pesquisadora possibilitou inferir como positiva a implementação do curso de extensão em questão. Durante a realização das tarefas, os participantes se mostravam envolvidos e interessados. Notou-se que eles interagiam, na maioria do tempo, fazendo uso da língua espanhola e trabalhavam ativamente na produção das atividades.

A primeira tarefa da WQ propôs que os participantes se dividissem em grupos de três ou quatro integrantes e discutissem sobre uma cidade ou capital de origem hispana que 
gostariam de visitar nas próximas férias. Além disso, eles deveriam externar suas preferências durante uma viagem especificando locais que gostam de visitar, o que gostam de fazer quando viajam, entre outras curiosidades. Após entrarem em um acordo, cada grupo apresentou à turma o local escolhido. Por fim, a professora pesquisadora realizou um sorteio que determinou qual grupo ficaria responsável por vender o pacote de viagem proposto como produto final para o outro.

A tarefa dois sugeriu a pesquisa e a seleção de fotos relacionadas aos pontos turísticos referentes ao país para o qual se deveria vender o pacote turístico. Após a seleção dessas fotos, cada grupo deveria produzir um pequeno vídeo com o material selecionado e postá-lo no Edmodo. Essa tarefa teve como objetivo aproximar os participantes de aspectos culturais e geográficos, uma vez que se entende que o aprendizado de uma língua adicional não deve ser abordado como um campo somente linguístico.

Enquanto os participantes realizavam a tarefa dois, foi possível perceber, em consonância com Mayrink e Albuquerque Costa (2017), a web como um recurso didático capaz de ampliar o espaço de aprendizagem autêntica e colaborativa e promover interações, uma vez que durante a busca e seleção das fotos na web, os alunos interagiam em língua espanhola, mostrando fotos e/ou contando algum fato sobre os lugares selecionados.

Como nos vídeos produzidos a partir do material encontrado na web não há a exibição dos participantes dessa pesquisa, foram postados pela pesquisadora no YouTube. Por meio do $Q R$ Code exposto na Figura 1 é possível acessar o vídeo produzido por um dos grupos.

Figura 1 - QR Code do vídeo produzido por um dos grupos

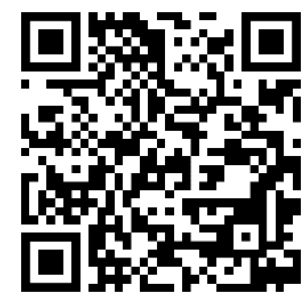

Fonte: Protocolo de pesquisa (2019).

De acordo com Bacich e Moran (2018), aprende-se mais profundamente a partir da prática, ou seja, do aprender fazendo aliado a ambientes ricos em oportunidades. Sendo assim, a tarefa três propôs a produção de um vídeo a partir de uma pesquisa sobre as condições climáticas do destino e período escolhidos pelos clientes. $\mathrm{O}$ aplicativo KineMaster ${ }^{5}$ foi sugerido para a realização dessa tarefa por permitir a produção de vídeos com a técnica Chroma Key ${ }^{6}$. Para isso, foi necessário reservar o estúdio de gravações disponível no local onde se deu a pesquisa. Ressalta-se, no entanto, que ainda que o espaço escolar não conte com um estúdio de gravação, a produção de vídeos pode ser feita por qualquer câmera, inclusive a do smartphone (TUMOLO, 2014) em qualquer lugar. A Figura 2 ilustra imagens capturadas do vídeo produzido por um dos grupos.

\footnotetext{
${ }^{5}$ Aplicativo previamente selecionado por apresentar versão gratuita e estar disponível para sistema Android e iOS.

${ }^{6}$ Prática que permite a troca do fundo da filmagem ou de uma fotografia utilizando um cenário de cor azul ou verde para posterior edição por meio de um software apropriado.
} 
Figura 2 - Imagens capturadas do vídeo produzido por um dos grupos

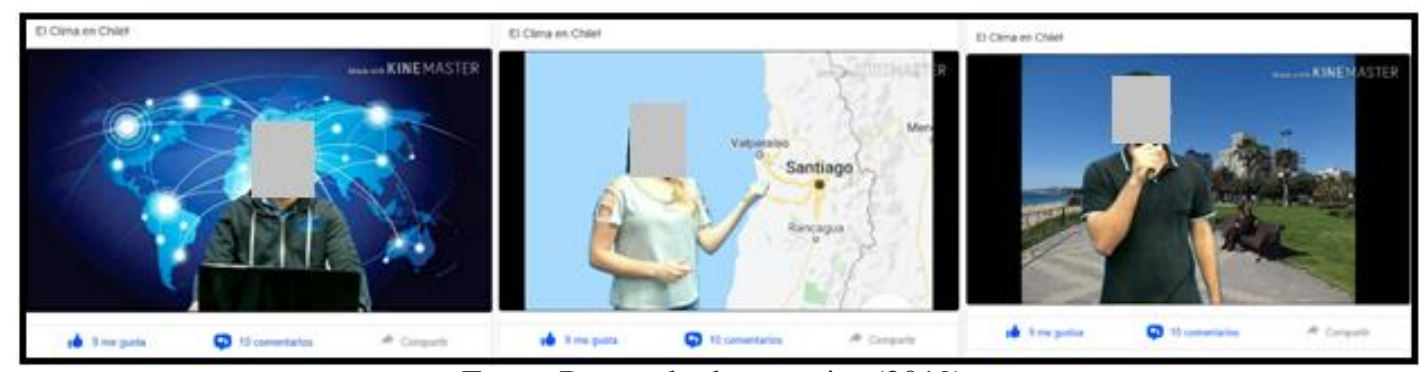

Fonte: Protocolo de pesquisa (2019).

Ao analisar aos vídeos produzidos na tarefa três, retomam-se as reflexões de Díaz Rodríguez (2012) e Oliveira (2013) a respeito das contribuições desse recurso no desenvolvimento da criatividade, da motivação e da interação ao constatar que essa atividade foi a que promoveu maior número de interações e reações com "me gusta" (curtidas) no AVA Edmodo. Essa percepção também vai ao encontro da premissa de Tumolo (2014) ao afirmar que quando usado como produção, o vídeo é capaz de tornar o aprendiz mais ativo e participativo.

A tarefa quatro propôs a produção de um vídeo sugerindo quais tipos e quantas peças de roupas deveriam ser levadas para a viagem. Com isso, foi possível retomar o vocabulário relacionado a roupas e acessórios. Os vídeos produzidos nessa tarefa não serão divulgados porque expõem a imagem dos participantes. Embora eles tenham assinado um termo de consentimento para a exibição de imagem e áudio, considerou-se importante manter o sigilo de sua participação.

Para produzirem esses vídeos, os participantes pesquisaram blogs e vídeos de digital influencers no YouTube. Os vídeos produzidos buscavam informar que roupas deveriam ser levadas na viagem e de que modo se deve organizar uma mala para essa ocasião. A análise desses vídeos permitiu perceber, devido à qualidade apresentada, o envolvimento deles na realização da tarefa.

Para realizar a tarefa cinco, cada grupo deveria pesquisar sobre alimentos e pratos típicos mais consumidos no destino escolhido, bem como os hábitos relacionados à alimentação no destino em que "seus clientes" passariam as próximas férias. Em seguida, deveriam preparar um cardápio utilizando o software Canva ${ }^{7}$ e postá-lo no Edmodo. Cada participante deveria comentar o cardápio elaborado para a viagem do seu grupo.

A análise das interações escritas nas postagens dos cardápios produzidos da tarefa cinco e do material produzido na tarefa seis permitiu compreender que os participantes demonstraram mais cuidado ao escrever seus comentários do que anteriormente. Durante o feedback feito a partir do diálogo reflexivo entre os envolvidos, a professora pesquisadora elogiou a qualidade dos trabalhos postados e das interações realizadas e destacou o desenvolvimento positivo da habilidade escrita. Diante disso, alguns comentários realizados pelos participantes foram registrados em um diário de campo. Sobre a qualidade dos trabalhos, um dos participantes comentou: "Nosso grupo sempre revisa antes de postar. Sempre passa algum errinho, mas a

\footnotetext{
${ }^{7}$ O Canva é um software que oferece uma infinidade de templates pré-definidos que podem servir como base para criar, de forma simples, on-line e colaborativa diferentes tipos de design (como logotipos, cardápios, panfletos, entre outros) para diversas mídias. Além da versão web, está disponível também para smartphones com sistema Android e iOS. Possui uma versão gratuita e uma paga. Em ambas é possível encontrar uma variedade de recursos. Disponível em: https://www.canva.com/.
} 
gente tenta corrigir.". Já sobre a escrita, outro participante revelou que "Agora nós temos mais cuidado ao escrever porque sabemos que todos vão ler.".

Esses comentários reforçam o papel da web como um espaço privilegiado para o aprendizado de línguas (PAIVA, 2001) tanto por permitir ampliar o conhecimento por meio das buscas de informações e consequente contato com materiais autênticos, quanto como pelo cuidado que os participantes tiveram ao escrever por saber que, por estarem em um AVA, outros poderiam ler, não somente a professora pesquisadora.

A tarefa seis propôs uma pesquisa relacionada aos tipos de hospedagem, preços e às condições de pagamento para diárias, bem como ao horário e valores de passagens aéreas. A partir disso, eles deveriam preparar um material utilizando o Canva ou o Powerpoint e postá-lo no Edmodo para que o grupo cliente pudesse avaliar. Assim como nas demais atividades, os participantes apresentaram-se comprometidos e desenvolveram a tarefa com qualidade.

Findada a realização das tarefas, os participantes deram início à elaboração do produto final, que consistiu na produção de uma propaganda com o intuito de vender um pacote de viagem. Cada grupo teve a oportunidade de "vender seu pacote de viagem" (apresentar o produto final) e os "clientes", deveriam dar o feedback, dizendo se comprariam ou não esse produto.

Esse produto deveria envolver todos os aspectos trabalhados nessas tarefas, ou seja, tudo o que fora pesquisado para a realização dessas, serviria de base para a sua produção. Desse modo, a propaganda deveria conter indicação de visitação a lugares turísticos (tarefa dois), as condições climáticas durante o período escolhido para a viagem (tarefa três), dicas de roupas e acessórios para serem levados, considerando o clima e as atividades que eles poderiam exercer (tarefa quatro), indicação de restaurantes e pratos típicos (tarefa cinco) e preços e condições de pagamento para os bilhetes aéreos e hospedagem (tarefa seis).

A avaliação da apresentação do grupo foi feita pela professora pesquisadora, que destacou aspectos relacionados à oralidade. Os participantes elaboraram e apresentaram muito bem seus produtos e, assim como nas tarefas anteriores, foram cuidadosos em sua elaboração.

Os participantes deram seu feedback quanto ao produto exposto considerando os aspectos destacados no elemento "avaliação" constante na WQ: a aparência, clareza na apresentação, criatividade e se o produto atendeu às expectativas do grupo "cliente".

A Figura 3 ilustra um $Q r$ Code que direciona a um dos vídeos produzidos como produto final. Esse vídeo foi escolhido por não ter exibido a imagem dos participantes em sua produção.

Figura 3 - QR Code do produto final produzido por um dos grupos

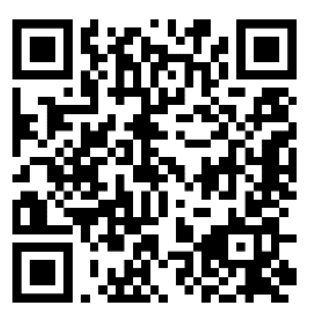

Fonte: Protocolo de pesquisa (2019).

Diante do exposto, retoma-se as reflexões de Moran (2009), Díaz Rodríguez (2012), Oliveira (2013), Tumolo (2014) e Bastos e Ramos (2015) e infere-se que a produção de vídeos apresenta-se como uma proposta capaz de não só motivar o interesse pela aprendizagem por 
colocar o aprendiz no centro do processo de ensino e aprendizagem como também potencializar a interação.

\subsection{Questionário final}

Considerando a proposta de atividades que requeriam a produção de vídeos por parte dos participantes, buscou-se, por meio das perguntas elaboradas no questionário final, saber a opinião deles a respeito dessa experimentação.

A Tabela 2 apresenta o quantitativo das respostas dos alunos referentes à primeira pergunta relacionada à produção de vídeos como recurso potencializador da aprendizagem do espanhol como língua adicional. Para tanto, considerou-se a escala: 5 - Concordo; 4 - Concordo parcialmente; 3 - Não concordo nem discordo; 2 - Discordo parcialmente; 1 - Discordo.

Tabela 2 - Respostas dos participantes referentes à primeira questão relacionada à produção de vídeos

\begin{tabular}{lcccc}
\hline \multicolumn{1}{c}{ Produção de vídeos como recurso potencializador da aprendizagem do espanhol como língua adicional } \\
\hline \multicolumn{1}{c}{ Assertivas } & 5 & 4 & 3 & 2 \\
\hline 1.1 A produção dos vídeos proposta pelas atividades potencializou a & 11 & 2 & \\
aprendizagem da língua espanhola. & & & \\
1.2. Motivou o aprendizado do idioma. & 11 & 2 & \\
13. Proporcionou uma aprendizagem mais participativa (ativa). & 11 & 2 & \\
1.4 Permitiu maior interação com os colegas e com a professora. & 10 & 3 & \\
1.5 Promoveu uma aprendizagem colaborativa. & 11 & 2 & \\
1.6 Despertou o interesse em produzir vídeos com outros conteúdos. & 5 & 5 & 2 & 1 \\
\hline
\end{tabular}

Fonte: Elaboração própria, a partir de dados da pesquisa (2019).

Segundo os dados expostos na Tabela 2, nota-se que foram frequentes as respostas nas opções 5 e 4 em quase todas as assertivas, sinalizando que os participantes concordaram ou concordaram parcialmente. No entanto, no que diz respeito à produção de vídeos com outros conteúdos, as avaliações foram mais equilibradas, apesar de a maioria ter opinado concordar ou concordar parcialmente com essa afirmação.

Com os dados coletados nessa questão é possível inferir que a produção de vídeos é uma proposta capaz de motivar a construção do conhecimento, promover uma aprendizagem mais ativa, colaborativa e interativa.

A segunda questão buscou saber sobre o processo de escrita do roteiro dos vídeos. Nela foi perguntado sobre a frequência em que a língua espanhola foi utilizada durante a escrita e a oralidade. Conforme ilustra o Gráfico 1, 61,5\% dos participantes, oito deles, afirmaram tê-la utilizado com frequência e o restante, $38,5 \%, 5$ participantes, afirmaram terem feito uso da língua durante todo o tempo em que escreviam o roteiro dos vídeos.

Gráfico 1 - Frequência do uso da língua espanhola na habilidade escrita

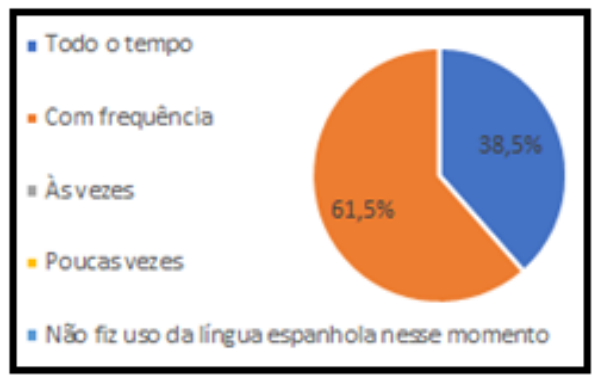

Fonte: Protocolo de pesquisa (2019). 
Em relação à prática da oralidade, ou seja, ao uso da língua espanhola durante a realização das tarefas e discussão de ideias com o grupo, 11 participantes $(84,6 \%)$ afirmaram terem feito com frequência e os outros dois alunos, que correspondem a $15,4 \%$, disseram que fizeram às vezes.

Para Tumolo (2014), a língua que se deseja aprender deve ser priorizada não só no vídeo elaborado. Segundo ele, a língua deve estar presente em todos os momentos que envolvem a aprendizagem por meio desse recurso: desde as instruções da tarefa que se quer desenvolver com os vídeos e as discussões e reflexões iniciais realizadas para sua elaboração até o recebimento de comentários na forma de feedback. Diante disso e considerando os resultados obtidos na pergunta dois, infere-se que as tarefas propostas pela WQ contribuíram para o desenvolvimento da habilidade oral e escrita dos participantes.

O Quadro 1 sintetiza a avaliação dos alunos quanto à produção dos vídeos a partir da pergunta: "De modo geral, como você avalia o trabalho de produção dos vídeos propostos para a aprendizagem do espanhol?".

Quadro 1 - Produção dos vídeos: potencialidades e desafios

\begin{tabular}{|l|l|}
\hline \multicolumn{2}{|c|}{ De modo geral, como você avalia o trabalho de produção dos vídeos propostos para a aprendizagem } \\
do espanhol
\end{tabular}

Fonte: Próprios autores, a partir de dados coletados na pesquisa (2019).

Os desafios apontados pelos participantes da presente pesquisa sinalizam a necessidade de se considerar que, apesar de as tecnologias digitais se fazerem presentes em seu cotidiano, seu uso para fins pedagógicos ainda requer uma atenção especial. Nesse sentido, é preciso que o professor esteja consciente de que nem sempre a facilidade de uso dessas tecnologias para fins pessoais será suficiente para sua utilização no processo de ensino e aprendizagem. Devese, portanto, buscar reconhecer previamente as habilidades dos estudantes e utilizá-las a favor desse processo.

Quanto à referência a respeito das interações terem ocorrido principalmente entre os participantes do próprio grupo, observa-se que é possível que eles não tenham considerado as interações realizadas entre todos no Edmodo. Tampouco devem ter ponderado a avaliação dinâmica, que tem como característica principal a interação por meio da mediação (FIGUEIREDO, 2019) realizada a partir da intervenção entre os participantes e a professora pesquisadora ao longo de todo o curso de extensão.

Diante do exposto e consoante às reflexões de Tumolo (2014), infere-se que a produção de vídeos fomentou o trabalho com as habilidades linguísticas e tornou o processo de aprendizagem mais dinâmico, ativo e contribuiu para o aprimoramento do espanhol como língua adicional. 


\section{Considerações finais}

A utilização de tecnologias digitais se tornou uma realidade em nosso cotidiano e, da mesma forma, tem sido frequente o seu uso também para fins pedagógicos. No entanto, entende-se que o uso dessas tecnologias no processo de ensino e aprendizagem necessita estar acompanhada por atividades que fomentem o protagonismo do estudante por meio de atividades que o permitam refletir, criar, colaborar e interagir.

Diante disso, este artigo teve como objetivo apresentar os resultados de uma intervenção pedagógica realizada com treze estudantes que concluíram o curso de espanhol do Centro de Línguas de um Instituto Federal de Educação Ciência e Tecnologia. Essa intervenção ocorreu por meio de um curso de extensão que visou investigar de que maneira a produção de vídeos pode promover melhorias no processo de ensino e aprendizagem do espanhol como língua adicional, de modo a torná-lo mais interativo e ativo.

Quando planejada, a utilização de tecnologias digitais, bem como da web, pode constituir-se como um recurso favorável a uma prática pedagógica que corresponde às necessidades atuais. No âmbito do ensino e aprendizagem de línguas adicionais, essas tecnologias podem ainda contribuir consideravelmente para o desenvolvimento da língua que se deseja aprender e/ ou aprimorar, haja vista os resultados obtidos.

Segundo a avaliação dos participantes, os vídeos produzidos motivaram o aprendizado, proporcionaram uma aprendizagem mais ativa, promoveram a interação, o trabalho colaborativo e uma postura mais autônoma na construção do aprendizado. Entretanto, eles também apontaram a necessidade de se refletir sobre as habilidades para o uso de tecnologias digitais pelos estudantes.

Espera-se que esta pesquisa fomente investigações de propostas similares e contribua com o desenvolvimento de práticas pedagógicas que evidenciem o protagonismo do aprendiz, tornando o processo de ensino e aprendizagem mais ativo e interativo.

\section{Referências}

ABAR, C. A. A. P.; BARBOSA, L. M. WebQuest: um desafio para o professor! São Paulo: Avercamp, 2008.

BACICH, L.; MORAN, J. Metodologias ativas para uma educação inovadora: uma abordagem teórico-prática. Porto Alegre: Penso, 2018.

BARDIN, L. Análise de conteúdo. 5. ed. Lisboa: Edições 70, 2009.

BASTOS, M. A. A.; RAMOS, M. A. S. Tecnologias e competências de pensamento na aprendizagem da língua estrangeira-inglês. Revista e-Curriculum, São Paulo, v.13, n. 3, p. 589-609, 2015. Disponível em: https://www.redalyc.org/pdf/766/76642173011.pdf. Acesso em: 20 jun. 2019.

BOTTENTUIT JUNIOR, J. B. Uso da ferramenta podcast e da metodologia webquest na educação a distância. Revista EducaOnline, Rio de Janeiro. v. 7, n. 3, p. 16-32, 2013. Disponível em: 
http://www.latec.ufrj.br/revistas/index.php?journal=educaonline\&page=article\&op=view\&pat h\%5B\%5D=512. Acesso em: 9 abr. 2019.

COSTA, F. A.; CARVALHO, A. A. A. WebQuests: Oportunidades para alunos e professores. In: ENCONTRO SOBRE WEBQUEST, 2006, Braga. Anais [...] Braga: Universidade do Minho, 2006, p. 8-25.

DAMIANI, M. F. Sobre pesquisas do tipo Intervenção. In: ENCONTRO NACIONAL DE DIDÁTICA E PRÁTICAS DE ENSINO, 16., 2012, Campinas. Anais [...] Campinas: Universidade Estadual de Campinas, 2012, p. 2882-2890.

DAMIANI, M. F. et al. Discutindo pesquisas do tipo intervenção pedagógica. Cadernos de Educação, Pelotas, n.45, p.57-67, 2013. Disponível em:

https://periodicos.ufpel.edu.br/ojs2/index.php/caduc/article/view/3822. Acesso em: 23 maio 2019.

DÍAZ RODRÍGUEZ, E. El vídeo de producción propia como recurso didáctico en el aula ELE. Luces, cámara, ¡acción! In: CONGRESO INTERNACIONAL DE LA ASELE, 23. 2012, Girona. Anais [...] Girona: Asociación para la Enseñanza del Español como Lengua Extranjera, 2012, p. 353-357.

DODGE, B. Creating a Rubric for a Given Task. 1999. Disponível em: http://projects.edtech.sandi.net/staffdev/tpss99/rubrics/rubrics.html. Acesso em: 10 fev. 2019.

FIGUEIREDO, F. J. Q. de. Vygotsky: a interação no ensino/aprendizagem de línguas. São Paulo: Parábola, 2019.

GERHARDT, T. E.; SILVEIRA, D. T. Métodos de pesquisa. Porto Alegre: UFRGS, 2009.

GIL, A. C. Como elaborar projetos de pesquisa. 5. ed. São Paulo: Atlas, 2010.

MARCH, T. The Learning Power of WebQuests. Educational Leadership, v. 61, n. 4, p. 4247, 2004. Disponível em: https://tommarch.com/writings/ascdwebquests/. Acesso em: 06 fev. 2019.

MAYRINK, M. F.; ALBUQUERQUE-COSTA, H. Ensino presencial e virtual em sintonia na formação em línguas estrangeiras. The ESPecialist: Descrição, Ensino e Aprendizagem, São Paulo, v. 38, n. 1, p. 1-14, jan./jul. 2017. Disponível em:

https://revistas.pucsp.br/esp/article/view/32218. Acesso em: 7 abr. 2019.

MENDES, D. S. G. A metodologia WebQuest como estratégia de ensino motivadora da aprendizagem da leitura e da escrita no $5^{\circ}$ ano do ensino fundamental. 2018. Dissertação (Gestão de Ensino da Educação Básica) - Universidade Federal do Maranhão, São Luís, 2018.

MORAN, J. M. O Vídeo na Sala de Aula. Revista Comunicação \& Educação, São Paulo, v. 2, p. 27-35, 1995. Disponível em: http://www.revistas.usp.br/comueduc/article/view/36131. Acesso em: 21 jun. 2019. 
MORAN, J. M. Vídeos são instrumentos de comunicação e de produção. Portal do Professor do MEC. 2009. Disponível em:

http://www.eca.usp.br/prof/moran/site/textos/tecnologias_eduacacao/videos.pdf. Acesso em: 3 jul. 2019.

OLIVEIRA, E. C. Navegar e preciso! - O uso de recursos tecnológicos para um ensino aprendizagem significativo de línguas estrangeiras. In: PEREIRA, A. L.; GOTTHEIM, L. (Orgs.) Materiais didáticos para o ensino de língua estrangeira: Processos de criação e contexto de uso. Campinas, SP: Mercado de Letras, 2013.

PAIVA, V. L. M. de O. e. A www e o Ensino de Inglês. Revista Brasileira de Linguística Aplicada, v. 1, n. 1, p. 93-116, 2001. Disponível em:

http://www.scielo.br/pdf/rbla/v1n1/06.pdf. Acesso em: 17 maio 2019.

PORTO, C. V. Interagindo e aprendendo com a tecnologia: a webquest na sala de aula de línguas. The ESPecialist, v. 38, n. 1, p.1-18, 2017. Disponível em:

https://revistas.pucsp.br/index.php/esp/article/view/32221. Acesso em: 16 maio 2019.

SANTOS, J. A. dos. Ensino da língua inglesa: webquest, uma possibilidade de aprendizagem efetiva. 2019. Dissertação (Programa de Pós-graduação em Ensino de stricto sensu) - Instituto Federal de Educação, Ciência e Tecnologia de Mato Grosso - IFMT associado à Universidade de Cuiabá, Cuiabá, 2019.

SILVA, M. do R. C. da. Potenciar a competência comunicativa e sociocultural através de documentos audiovisuais na aula de espanhol língua estrangeira. 2016. Dissertação (Mestrado em Ensino de Português no $3^{\circ}$ Ciclo do Ensino Básico e Ensino Secundário e de Espanhol nos Ensinos Básico e Secundário) - Universidade do Minho, Braga, Portugal, 2016.

SILVA, A. L.; MARIANO, L. S.; FINARDI, K. R. As novas tecnologias no ensinoaprendizado de L2: refletindo a partir de olhares de professores. LínguaTec, Bento Gonçalves, v. 3, n. 6, p. 71-87, nov. 2018. Disponível em:

https://periodicos.ifrs.edu.br/index.php/LinguaTec/article/view/3290. Acesso em: 15 maio 2019.

TUMOLO, C. Recursos digitais e aprendizagem de inglês como língua estrangeira. A Journal of English Language, Literatures in English and Cultural Studies, n. 66, p. 203238, 2014. Disponível em: https://periodicos.ufsc.br/index.php/desterro/article/view/21758026.2014n66p203. Acesso em: 21 jan. 2019.

Recebido em agosto de 2020.

Aprovado em novembro de 2020. 